\title{
An Activated Protein C Analog Stimulates Neuronal Production by Human Neural Progenitor Cells via a PAR1-PAR3-S1PR 1 -Akt Pathway
}

\author{
Huang Guo, ${ }^{1 *}$ Zhen Zhao, ${ }^{1 \star}$ Qi Yang, ${ }^{1}$ Min Wang, ${ }^{1}$ Robert D. Bell, ${ }^{2}$ Su Wang, ${ }^{3}$ Nienwen Chow, ${ }^{4}$ Thomas P. Davis, ${ }^{5}$ \\ John H. Griffin, ${ }^{6}$ Steven A. Goldman, ${ }^{3}$ and Berislav V. Zlokovic ${ }^{1}$ \\ ${ }^{1}$ Center for Neurodegeneration and Regeneration, Zilkha Neurogenetic Institute and Department of Physiology and Biophysics, University of Southern \\ California, Keck School of Medicine, Los Angeles, California 90089, ${ }^{2}$ Center for Neurodegenerative and Vascular Brain Disorders and Department of \\ Neurosurgery, University of Rochester Medical Center, Rochester, New York 14642, ${ }^{3}$ Center for Translational Neuromedicine, Department of Neurology, \\ University of Rochester Medical Center, Rochester, New York 14642, ${ }^{4}$ ZZ Biotech, LLC, Rochester, New York 14642, ${ }^{5}$ Department of Medical Pharmacology, \\ Blood Brain Barrier Research Laboratory, College of Medicine, University of Arizona, Tucson, Arizona 85724, and ${ }^{6}$ Department of Molecular and \\ Experimental Medicine, The Scripps Research Institute, La Jolla, California 92037
}

Activated protein C (APC) is a protease with anticoagulant and cell-signaling activities. In the CNS, APC and its analogs with reduced anticoagulant activity but preserved cell signaling activities, such as 3K3A-APC, exert neuroprotective, vasculoprotective, and anti-inflammatory effects. Murine APC promotes subependymal neurogenesis in rodents in vivo after ischemic and traumatic brain injury. Whether human APC can influence neuronal production from resident progenitor cells in humans is unknown. Here we show that 3K3A-APC, but not S360A-APC (an enzymatically inactive analog of APC), stimulates neuronal mitogenesis and differentiation from fetal human neural stem and progenitor cells (NPCs). The effects of 3K3A-APC on proliferation and differentiation were comparable to those obtained with fibroblast growth factor and brain-derived growth factor, respectively. Its promoting effect on neuronal differentiation was accompanied by inhibition of astroglial differentiation. In addition, 3K3A-APC exerted modest anti-apoptotic effects during neuronal production. These effects appeared to be mediated through specific protease activated receptors (PARs) and sphingosine-1-phosphate receptors (S1PRs), in that siRNA-mediated inhibition of PARs 1-4 and S1PRs 1-5 revealed that PAR1, PAR3, and S1PR 1 are required for the neurogenic effects of 3K3A-APC. 3K3A-APC activated Akt, a downstream target of $\mathrm{S}_{1 \mathrm{PR}_{1}}$, which was inhibited by $\mathrm{S}_{\mathrm{PPR}}, \mathrm{PAR} 1$, and PAR3 silencing. Adenoviral transduction of NPCs with a kinasedefective Akt mutant abolished the effects of 3K3A-APC on NPCs, confirming a key role of Akt activation in 3K3A-APC-mediated neurogenesis. Therefore, APC and its pharmacological analogs, by influencing PAR and S1PR signals in resident neural progenitor cells, may be potent modulators of both development and repair in the human CNS.

\section{Introduction}

Activated protein C (APC) is a serine protease with anticoagulant and cell-signaling activities (Zlokovic and Griffin, 2011). It's cell-

Received Sept. 20, 2012; revised Feb. 23, 2013; accepted March 2, 2013.

Author contributions: H.G., Z.Z., R.D.B., J.H.G., S.A.G., and B.V.Z. designed research; H.G., Z.Z., Q.Y., and M.W. performed research; S.W., N.C., T.P.D., J.H.G., and S.A.G. contributed unpublished reagents/analytic tools; H.G., Z.Z., Q.Y., M.W., R.D.B., and B.V.Z. analyzed data; H.G., Z.Z., and B.V.Z. wrote the paper.

This work was supported by the National Institutes of Health (Grant \#HL63290 to B.Z., Grant \#HL52246 to J.H.G., and Grants \#R01NS75345 to R01NS39559 to S.G.), as well as by the New York Stem Cell Research Board. We thank Dr. Robert Freeman (University of Rochester Medical Center, Rochester, NY) for providing the Ad. Akt ${ }^{179 A}$ construct, Dr. Joe G.N. Garcia (University of Chicago, Chicago, IL) for providing the Ad.EDG1 construct, and Dr. Abhay Sagare and Theresa Barrett for technical help and discussion. The flow cytometry study and cell cycle analysis were performed at the University of Southern California Broad California Institute of Restorative Medicine Center Flow Cytometry Core Facility, which is supported by the National Cancer Institute Cancer Center Shared Grant 5 P30 CA014089 and the University of Southern California Provost Funds.

*H.G. and Z.Z. contributed equally to this work.

B.V.Z. is the scientific founder of ZZ Biotech, a biotechnology company with a focus on developing APC and its functional mutants for stroke and other neurological disorders. T.P.D. and J.H.G. are members of the Scientific Advisory Board of ZZ Biotech. The remaining authors declare no competing financial interests.

Correspondence should be addressed to Berislav V. Zlokovic, MD, PhD, Zilkha Neurogenetic Institute, Room 101, Keck School of Medicine, University of Southern California, 1501 San Pablo Street, Los Angeles, CA 90089. E-mail: zlokovic@usc.edu.

DOI:10.1523/JNEUROSCI.4491-12.2013

Copyright $\odot 2013$ the authors $\quad 0270-6474 / 13 / 336181-10 \$ 15.00 / 0$ signaling activities have been demonstrated in the heart, lung, kidney, liver, and CNS (Griffin et al., 2012). In the CNS, APC regulates various signaling pathways in the endothelium, neurons, and microglia, resulting in vasculoprotective, neuroprotective, and anti-inflammatory effects after an acute or chronic CNS injury (Zlokovic and Griffin, 2011; Zlokovic, 2011).

The stereospecific interactions of APC with blood factors Va and VIIIa involve the APC enzymatic active site region and APC residues termed exosites. Exosites can be mutated to diminish APC's anticoagulant activity without altering its cell-signaling activity (Gale et al., 2002; Mosnier et al., 2004, 2007). APCengineered mutants such as $3 \mathrm{~K} 3 \mathrm{~A}-\mathrm{APC}$ and $5 \mathrm{~A}-\mathrm{APC}$ provide APC variants in which the risk of serious bleeding caused by APC's anticoagulant activity is diminished while the cytoprotective activities are preserved. In animal models of stroke (Guo et al., 2009b; Wang et al., 2009, 2012), traumatic brain injury (Walker et al., 2010), amyotrophic lateral sclerosis (Zhong et al., 2009), and bacterial sepsis (Kerschen et al., 2007), these APC variants exerted beneficial effects that were equivalent to, and sometimes greater than, the wild-type recombinant APC (wt-APC). 
wt-APC and its signal-competent analogs cross the blood-brain barrier via the endothelial protein $\mathrm{C}$ receptor (Deane et al., 2009; Zhong et al., 2009) and exert direct neuroprotection in vivo and in vitro (Guo et al., 2004, 2009a,b; Liu et al., 2004). All APCs, including wt-APC and 3K3AAPC, act via the protease activated receptors (PARs) PAR1 and PAR3 to protect neurons from divergent sources of injury (Guo et al., 2004, 2009a, 2009b; Liu et al., 2004; Cheng et al., 2006; Wang et al., 2009). In addition to neuroprotection, murine recombinant wt-APC potentiates subependymal proliferation of neural progenitor cells (NPCs) in vivo in $\mathrm{PAR}^{+/+}$mice, but not PAR1 ${ }^{-/-}$mice, after ischemic (Thiyagarajan et al., 2008) or traumatic (Petraglia et al., 2010) brain injury. However, whether APC's potentiation of neuronal addition to the injured brain can be translated to humans and whether APC molecules can promote differentiation of human NPCs remain elusive. In addition, APC's membrane receptors and pathway(s) mediating signal transduction in NPCs are unknown. To address these questions, we investigated whether human recombinant 3K3A-APC, an APC analog with $>90 \%$ reduced anticoagulant activity under clinical assessment as a brain protection agent after acute ischemic stroke (Williams et al., 2012), can influence neurogenesis by fetal human NPCs (Wang et al., 2010). Given significant speciesrelated differences between murine and human APC systems in terms of coagulation and cell signaling (Guo et al., 2009a), the effects of human $3 \mathrm{~K} 3 \mathrm{~A}-\mathrm{APC}$ on human NPCs cannot be automatically extrapolated from earlier in vivo work with murine wtAPC in mice (Thiyagarajan et al., 2008). In parallel studies, we used a combination of siRNA knock-down and adenoviral transduction to assess both APC's membrane receptors and the signaling pathways by which they transduce 3K3A-APC's effects in human NPCs.

\section{Materials and Methods}

Reagents. Human recombinant 3K3A-APC, a gift from ZZ Biotech, was manufactured as described previously (Williams et al., 2012). This APC mutant carries three Ala residues that replace Lys191-Lys192-Lys193. S360A-APC, an enzymatically inactive mutant of APC that lacks cytoprotective activities, served as a negative control for some studies (Zhong et al., 2009).

For the Western blot analysis or immunostaining, the following antibodies were used: mouse monoclonal anti-human nestin antibody (1: 200; catalog \#MAB5326; Millipore); mouse monoclonal anti-bovine microtubule-associated protein $2 \mathrm{MAP} 2$ antibody, which cross-reacts with human MAP2 (1:500; Millipore; catalog \#MAB3418); mouse monoclonal anti-human $\beta 3$-Tubulin (1:500, TU-20; catalog \#4466; Cell Signaling Technology); mouse monoclonal anti-swine GFAP antibody, which cross-reacts with human GFAP (GA5, 1:500, catalog \#3670; Cell
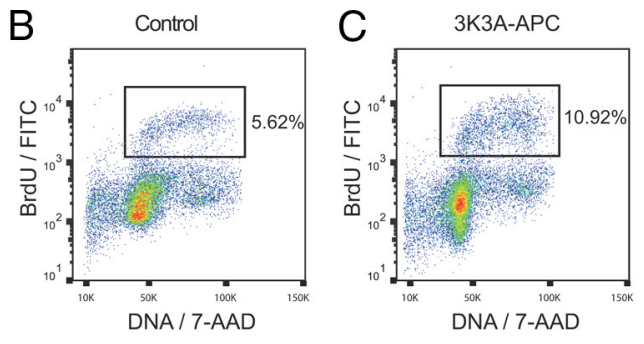

$E$

\begin{tabular}{|c|c|c|c|}
\hline & Control & 3K3A-APC & bFGF \\
\hline $\mathrm{G}_{0} / \mathrm{G}_{1}$ & $85.33 \pm 2.84 \%$ & $79.35 \pm 3.16 \%$ & $77.34 \pm 2.81 \%$ \\
\hline S-Phase & $7.94 \pm 0.82 \%$ & $\begin{array}{c}15.25 \pm 0.78 \% \\
(*)\end{array}$ & $\begin{array}{c}17.36 \pm 0.79 \% \\
(*)\end{array}$ \\
\hline $\mathrm{G}_{2} / \mathrm{M}$ & $6.72 \pm 0.84 \%$ & $5.40 \pm 0.98 \%$ & $5.28 \pm 0.83 \%$ \\
\hline
\end{tabular}

G

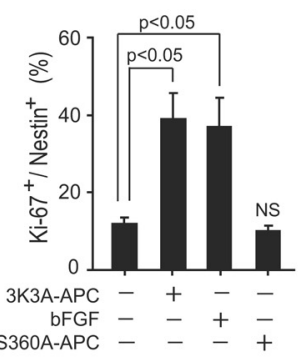

$\mathrm{H}$

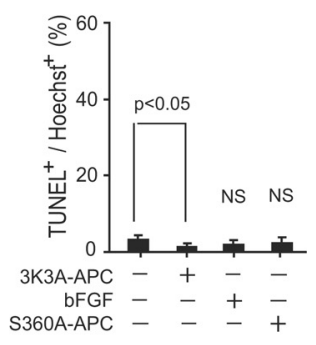

Figure 1. Human recombinant $3 \mathrm{~K} 3 \mathrm{~A}-\mathrm{APC}$ stimulates human NPC proliferation. $\boldsymbol{A}$, BrdU incorporation into human NPCs by ELISA $48 \mathrm{~h}$ after incubation with human $3 \mathrm{~K} 3 \mathrm{~A}-\mathrm{APC}$ at concentrations ranging from 0.5 to $5 \mathrm{~nm}$ compared with medium only (control) that has been arbitrarily taken as $100 \%$. (B-C) Representative FACS data showing the fraction of human NPCs (percentage) incorpo列 $48 \mathrm{~h}$ of incubation with vehicle and $3 \mathrm{~K} 3 \mathrm{~A}-\mathrm{APC}$ at $1.4 \mathrm{nM}$. D, FACS analysis of BrdU incorporation by proliferating Nan NPCs (percentage) at 2 DIV in the presence of vehicle, 3K3A-APC, bFGF, or S360A-APC at $1.4 \mathrm{~nm}(\boldsymbol{E})$. Cell cycle analysis based

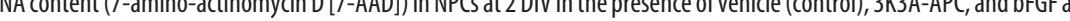
double staining in human NPCs 48 h after incubation with vehicle (control), 3K3A-APC, bGFG, or S360A-APC at 1.4 nM. G, Quantification of Nestin ${ }^{+} / \mathrm{Ki}_{-}-67^{+}$cells in human NPC cultures $48 \mathrm{~h}$ after incubation with vehicle (control), 3K3A-APC, bFGF, or S360AAPC at $1.4 \mathrm{~nm}$. $\boldsymbol{H}$, Quantification of TUNEL ${ }^{+} /$Hoechst $^{+}$cells in human NPCs cultures $48 \mathrm{~h}$ after treatment with $3 \mathrm{~K} 3 \mathrm{~A}-\mathrm{APC}$, bFGF, or S360A-APC at $1.4 \mathrm{~nm}$. In $\boldsymbol{A}, \boldsymbol{D}, \boldsymbol{E}, \boldsymbol{G}$, and $\boldsymbol{H}$, data are shown as mean \pm SEM, $n=3$ independent cultures in triplicates. Statistical significance was determined by one-way ANOVA followed by Tukey's post hoc test. NS indicates not significant.

Signaling Technology); mouse monoclonal oligodendrocyte marker O4 antibody, which detects human oligodendrocyte marker O4 (clone O4, 1:200; catalog \#MAB1326; R\&D Systems); rabbit polyclonal anti-human Ki-67 (1:200; catalog \#AB9260; Millipore); rabbit polyclonal anti-mouse phospho-Akt (pAkt, Ser473) antibody, which cross-reacts with human pAkt (1:1000; catalog \#9271; Cell Signaling Technology); rabbit polyclonal anti-mouse Akt antibody, which cross-reacts with human Akt (1:1000; catalog \#9272; Cell Signaling Technology). We used the following cleavage-site-blocking anti-PAR antibodies (all from Santa Cruz Biotechnology): polyclonal rabbit against human PAR1 (H-111; catalog \#sc-5605); monoclonal mouse against human PAR2 (SAM11; catalog \#sc-13504); polyclonal rabbit against human PAR3 (H103; catalog \#sc-5598). As reported, these antibodies cross-react with their corresponding mouse and human PARs (Riewald et al., 2002; Guo et al., 2004; Guo et al., 2009b).

SYTOX Green Nucleic Acid (Invitrogen) and Hoechst 33342 (Invitrogen) were used for nucleic staining. Additional reagents included: VPC $23019\left(\mathrm{~S}_{\mathrm{PR}} / \mathrm{S}_{1} \mathrm{PR}_{3}\right.$ receptor antagonist; catalog \#857360; Avanti Polar 
A

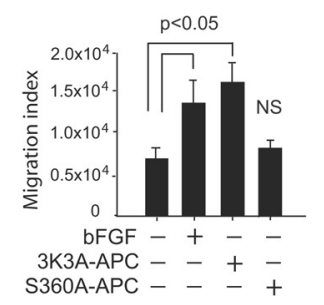

B

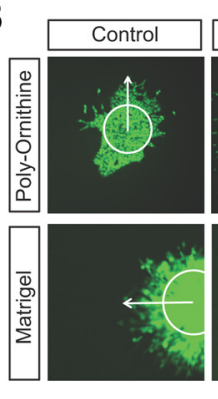

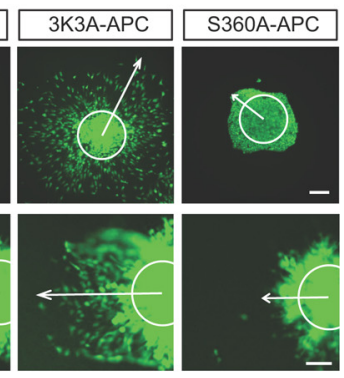

C

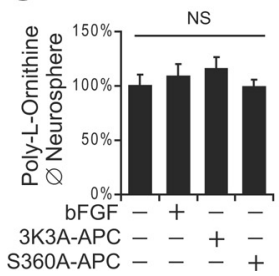

D

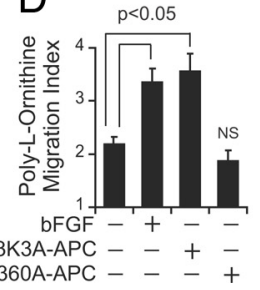

$E$

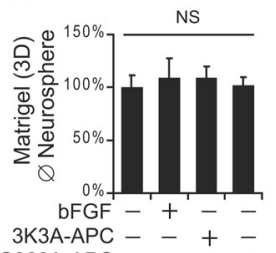

Figure 2. Human recombinant 3K3A-APC increases migration of human NPCs. A, Migration of NPCs determined in a Boyden chamber $5 \mathrm{~h}$ after plating with or without human 3K3A-APC, bFGF, or S360A-APC at $1.4 \mathrm{~nm}$. The migration index represents the number of migrated cells based on relative fluorescence units. $\boldsymbol{B}$, Representative neurospheres labeled with Cell Tracker Green CMFDA $16 \mathrm{~h}$ after plating on poly-L-ornithine-coated surface (top) or in 3D Matrigel (bottom) with vehicle, 3K3A-APC, or S360AAPC at $1.4 \mathrm{~nm}$. Solid circle denotes the neurospheres; arrow shows the leading edge of migrating cells. Scale bar, $100 \mu \mathrm{m}$. (C-D) Quantification of neurosphere migration cultured on poly-t-ornithine surface as in $\boldsymbol{B}$ (top) showing the size of neurospheres ( $\Phi$ : diameter; $\boldsymbol{C}$ and the migration index (D). $\boldsymbol{E}, \boldsymbol{F}$, Quantification of neurospheres cultured in 3D Matrigel as in $\boldsymbol{B}$ (bottom) showing the size of neurospheres $(\Phi$ : diameter; $\boldsymbol{E})$ and the migration index $(\boldsymbol{F})$. In $\boldsymbol{A}$ and $\boldsymbol{C}-\boldsymbol{F}$, data are shown as mean \pm SEM, $n=3$ independent cultures in triplicate. In $\boldsymbol{C}$ and $\boldsymbol{E}$, the control neurosphere diameter was arbitrarily taken as $100 \%$. Statistical significance was determined by one-way ANOVA followed by Tukey's post hoc test. NS indicates not significant.

Lipids), LY294002 (PI3 kinase inhibitor; catalog \#9901; Cell Signaling Technology). The antisense Ad.EDG1 was constructed as described previously (Schaphorst et al., 2003) and was generously provided by Dr Joe G.N. Garcia (University of Chicago, Chicago, IL). Recombinant human fibroblast growth factor-basic (bFGF; catalog \#F0291) and human brainderived neurotrophic factor (BDNF, catalog \#B3795) were purchased from Sigma.

Human NPCs. Human NPCs were obtained from the telencephalic ventricular zone (VZ)/subventricular zone (SVZ) of fetal brain tissue of either sex at 16-23 weeks gestational age within $2 \mathrm{~h}$ of extraction under a protocol approved by the Research Subjects Review Board of the University of Rochester Medical Center as described previously (Wang et al., 2010). Briefly, brain samples were collected into Ca/Mg-free Hank's buffered saline solution (HBSS) and dissected to separate the telencephalic VZ/SVZ from nonventricular parenchyma. The telencephalic VZ/ SVZ was dissociated as described previously (Wang et al., 2010). The cells were resuspended in DMEM/F12/N2 supplemented with $20 \mathrm{ng} / \mathrm{ml}(1.4$ nM) bFGF (Sigma) and plated in suspension culture dishes (Corning).

Cell proliferation assays. For bromodeoxyurinidine (BrdU) incorporation assay, NPCs (passage 2) were placed on poly-L-lysine-coated 12well plates at the density of $2 \times 10^{5}$ cells/well in DMEM/F12/N2 medium with or without $3 \mathrm{~K} 3 \mathrm{~A}-\mathrm{APC}$ and incubated for $48 \mathrm{~h}$. BrdU (10 $\mu \mathrm{M}$ ) was added to the medium for $30 \mathrm{~min}$ to label proliferating cells. The cells were fixed and the incorporated BrdU was measured using an ELISA kit (Roche) according to the manufacturer's instructions, as described previously (Harada et al., 2004). Briefly, after removing the labeling medium, the cells were fixed and the DNA was denatured in one step by adding FixDenat solution. After removing FixDenat, the BrdU incorporated into the newly synthesized cellular DNA was detected by the anti-BrdU-POD antibody and subsequent substrate reaction. The reaction product was quantified by using a plate reader (PerkinElmer) with a standard ELISA protocol. In these studies, $3 \mathrm{~K} 3 \mathrm{~A}-\mathrm{APC}$ was used at different concentrations (i.e., $0.5,1,1.5,2$, and $5 \mathrm{nM})$.

To determine the fraction of proliferating NPCs and to perform the cellcycle analysis, NPCs were labeled with a FITC BrdU Flow Kit (catalog
$\mathrm{F}$

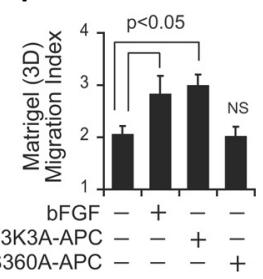

\#559619; BD Pharmingen) following the manufacturer's instructions and then analyzed using flow cytometry (Robey et al., 1996). The percentage of proliferating $\mathrm{BrdU}^{+}$cells stained with FITC-conjugated anti-BrdU antibody was determined by fluorescence-activated cell sorting. The DNA content of individual cells was determined by 7 -amino-actinomycin $\mathrm{D}$ staining and fluorescence-activated cell sorting and was analyzed using ModFit LT software (Verity Software House).

To determine the number of Nestin ${ }^{+} / \mathrm{Ki}$ $67^{+}$cells, NPCs (passage 2) were plated on poly-L-lysine-coated 6-well plates at the density of $4 \times 10^{5}$ per well in DMEM/F12/N2 medium with or without $3 \mathrm{~K} 3 \mathrm{~A}-\mathrm{APC}$ and incubated for $2 \mathrm{~d}$. The cells were double stained for nestin and Ki-67. Images were obtained using a confocal Zeiss LSM 510 Axioscope 2 microscope. Nestin ${ }^{+} / \mathrm{Ki}-67^{+}$cells were counted from 15 randomly selected $(210 \times 210 \mu \mathrm{m})$ images using ImageJ software $(n=200)$.

Cell migration assay. NPC migration was determined by a modified Boyden chamber assay, as described previously (Sun et al., 2004). A 96-well cell migration kit was used (Millipore) and each well was separated into two chambers by a membrane with $20 \mu \mathrm{m}$ pores. Human NPCs were resuspended in DMEM/F12/N2 containing $20 \mathrm{ng} / \mathrm{ml} \mathrm{bFGF}$ and replated in suspension culture dishes for $24 \mathrm{~h}$, and then medium was replaced with DMEM/F12/N2 medium without bFGF. The cells $\left(4 \times 10^{5}\right.$ cells $/ \mathrm{ml}$ in $100 \mu \mathrm{l}$ ) were placed into the upper chamber in DMEM/F12/N2 medium with or without 3K3A-APC. After $5 \mathrm{~h}$ of incubation at $37^{\circ} \mathrm{C}$, the migratory cells on the bottom of the insert membrane were dissociated from the membrane by incubation with cell detachment buffer. These cells were subsequently lysed and stained with CyQuantGR dye (Millipore), which exhibits strong fluorescence enhancement when bound to cellular nucleic acids. Fluorescence was measured with a fluorescence plate reader with a $480 / 520 \mathrm{~nm}$ filter set (PerkinElmer). Fluorescence intensity was used as migration index.

For the neurosphere migration assay on poly-L-ornithine-coated surface, the neurospheres ( $200 \pm 20 \mu \mathrm{m}$ in diameter) established with bFGF as described previously (Keyoung and Goldman, 2001; Karumbayaram et al., 2009; Wang et al., 2010) were carefully selected from passage 2 human NPCs under a light microscope (TS-100; Nikon) and transferred with transfer pipets (VWR International) to 48 -well plates (5 neurospheres/well) coated with poly-L-ornithine $(10 \mathrm{mg} / \mathrm{ml})$, as described previously (Kong et al., 2008). For the neurosphere migration experiment in 3D Matrigel, the neurospheres (5/well) were mixed with $20 \mu$ l of Matrigel (BD Biosciences) and plated in 48-well plates as 3D cultures, as described previously (Durbec et al., 2008). The cells were cultured in DMEM/ F12/N2 with vehicle (control), bFGF, 3K3A-APC, or S360A-APC for $16 \mathrm{~h}$, and then labeled with Cell Tracker Green CMFDA (Invitrogen) for $30 \mathrm{~min}$ at $37^{\circ} \mathrm{C}$, followed by washing with PBS and fixation with $4 \%$ paraformaldehyde.

Images of the neurospheres and migrating cells were obtained with an inverted fluorescence microscope (DMI6000B, Leica Microsystems) and analyzed with ImageJ software. Migration index was quantified as the ratio between the leading edge of radially migrating cells and the original neurosphere radius (Durbec et al., 2008). The migration index of 1 indicates that no migration was observed. An increase in the migration index by 1 indicates that cells migrated an extra distance equal to the radius of the neurosphere. For each experimental condition, 50 neurospheres were analyzed. The effects of $3 \mathrm{~K} 3 \mathrm{~A}-\mathrm{APC}$ and bFGF were compared at a concentration of $1.4 \mathrm{~nm}$.

Cell differentiation assay. Human NPCs (passage 2) were plated on poly-L-ornithine- $(10 \mu \mathrm{g} / \mathrm{ml})$ and laminin $(10 \mu \mathrm{g} / \mathrm{ml})$-coated 6-well 
plates at a density of $4 \times 10^{5}$ per well in DMEM/F12/N2 medium with or without 3K3A-APC, BDNF, or S360A-APC at $1.4 \mathrm{~nm}$, and incubated for 5 or $10 \mathrm{~d}$ in vitro (DIV) to allow for differentiation. Growth medium was changed every $3 \mathrm{~d}$ with addition of fresh medium with and without $3 \mathrm{~K} 3 \mathrm{~A}-\mathrm{APC}$, BDNF, or S360A-APC. At 5 and 10 DIV, the cells were immunostained for the neuronal markers $\beta 3$ tubulin or MAP2, the astrocyte marker GFAP, the oligodendrocyte marker O4, and Hoechst nuclear stain for the assessment of total number or percentage of each cell lineage. $\beta 3$-tubulin ${ }^{+}$or $\mathrm{MAP} 2^{+}$neurons, $\mathrm{GFAP}^{+}$astrocytes, and ${ }^{+}{ }^{+}$ oligodendrocytes were counted from 15 randomly selected $(210 \times 210 \mu \mathrm{m})$ fields for each culture condition using ImageJ software and were expressed as a percentage of the total number of cells $(n=200)$.

For the measurement of neurite length, a total number of $50 \mathrm{MAP}^{+}{ }^{+}$cells from each culture condition were analyzed. Total neurite length per cell was quantified by measuring the length of all neuritic processes on each cell using ImageJ software.

In some experiments, the effects of $3 \mathrm{~K} 3 \mathrm{~A}$ APC on neuronal differentiation were studied in older passage 6 NPCs under the same experimental conditions as above, and the percentage of $\beta 3$-tubulin ${ }^{+}$neurons was determined.

Detection of apoptosis. Apoptotic cells were visualized by in situ terminal deoxynucleotidyl transferase-mediated digoxigenin-dUTP nickend labeling (TUNEL) assay according to the manufacturer's instructions (DeadEnd Fluorometric TUNEL system; catalog \#G3250; Promega). Cells were counterstained with the DNA-binding fluorescent dye Hoechst 33342 (Invitrogen) at $10 \mu \mathrm{g} / \mathrm{ml}$ for $10 \mathrm{~min}$ at room temperature to reveal nuclear morphology. The rate of apoptosis was expressed as the percentage of TUNEL ${ }^{+}$cells for each cell type studied. The cells were counted in 10-20 random fields ( $n=400,200 \times$ magnification) by two independent observers blinded to the experimental conditions.

Silencing through RNA interference. Small interfering RNA (siRNA) targeting human PAR1, PAR2, PAR3, and PAR4; S1PR1, S1PR2, S1PR3, S1PR4, and S1PR5; sphingosine kinase 1 (Sphk-1) and Sphk-2; and negative control siRNAs were purchased from Dharmacon. siRNAs were delivered to the human NPC using the siPORTamine system (Ambion) according to the manufacturer's instructions. After $48 \mathrm{~h}$ of transfection, cells were verified for target gene knockdown by Western immunoblotting analysis or replaced with fresh medium for further experiments. For the cell differentiation assay, the knock-down efficiency was assessed by quantitative PCR (CFX-96; Bio-Rad) at 2 and 5 DIV. Primers were chosen from the Primer Bank at the Massachusetts General Hospital.

Construction of Ad.Akt ${ }^{\mathrm{K} 179 \mathrm{~A}}$. The kinase-inactive dominant-negative $\mathrm{Akt}^{\mathrm{K} 179 \mathrm{~A}}$ construct (Guo et al., 2011) was cloned into a GFP-containing adenoviral vector using AdEasy XL system (Stratagene). The adenoviral product containing $\mathrm{Akt}^{\mathrm{K} 179 \mathrm{~A}}$ was proliferated in HEK-293A cells (ATCC) and purified using the ViraKit (Virapur). The cells were transduced with adenoviral constructs (200 MOI) $24 \mathrm{~h}$ before performing subsequent experiments. The transduction efficiency was determined by GFP signal and Western blot analysis.
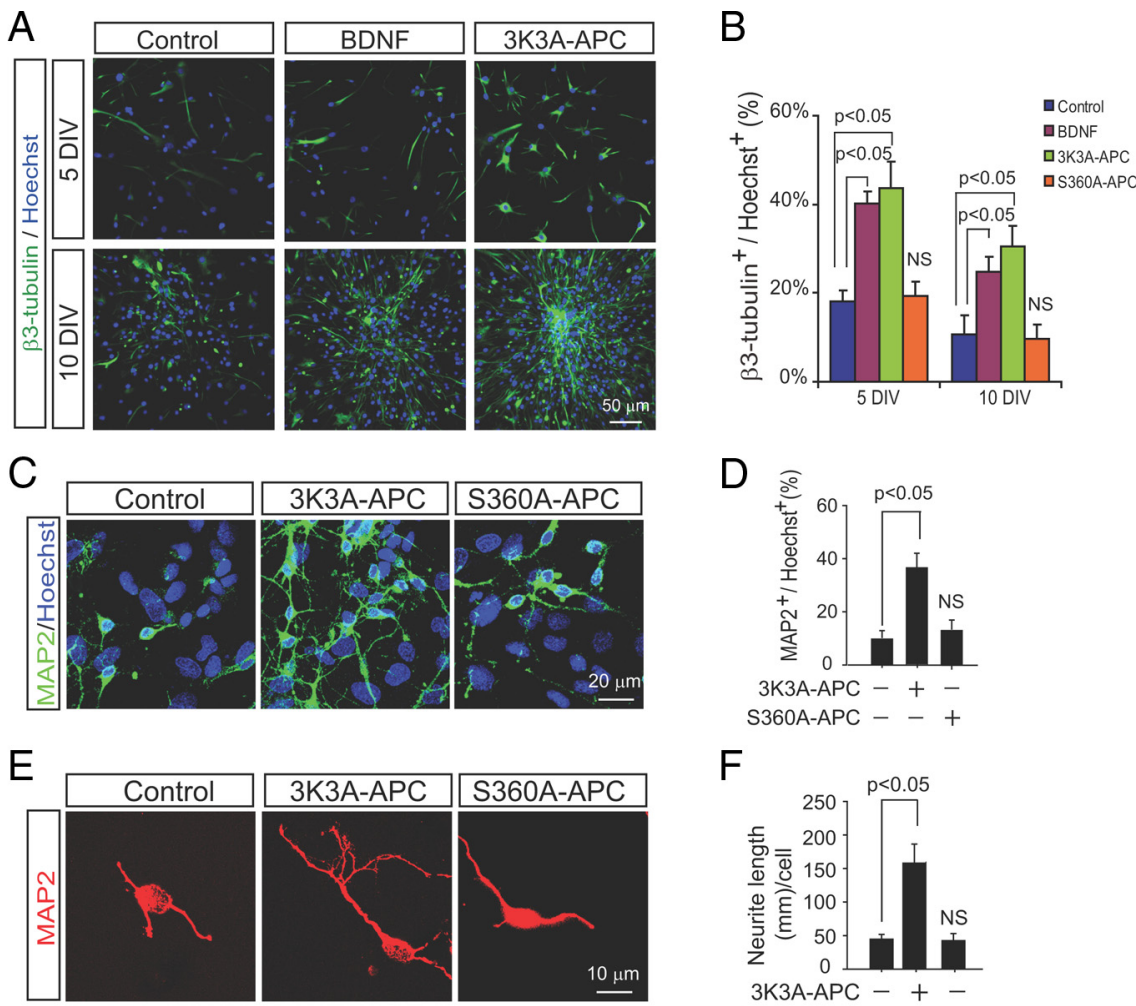

F
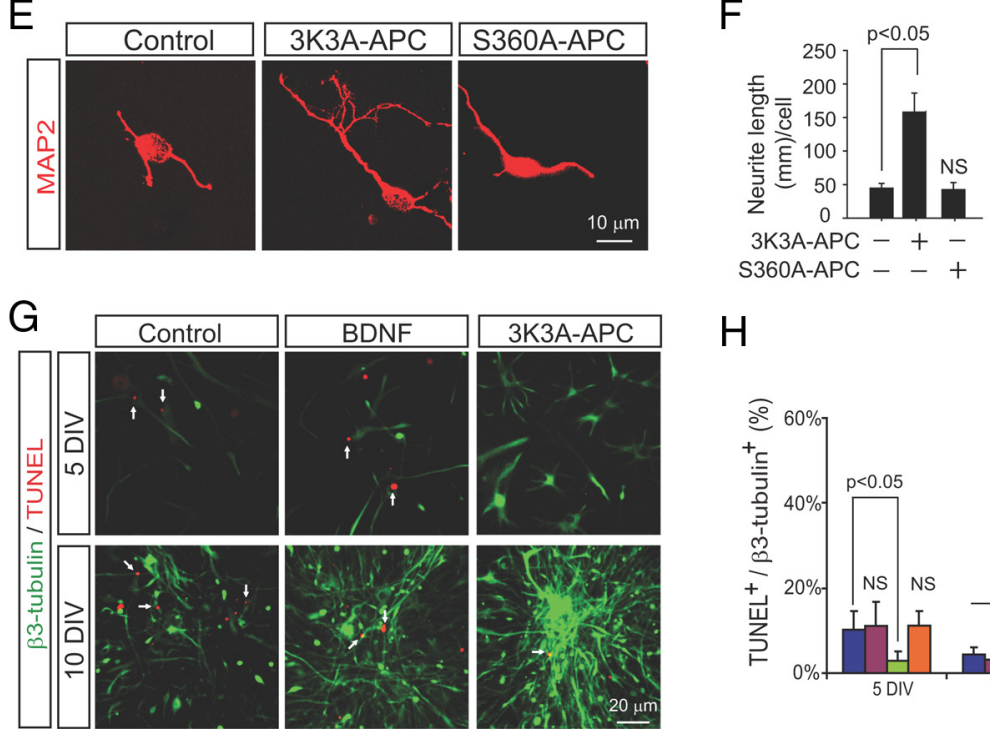

$\mathrm{H}$

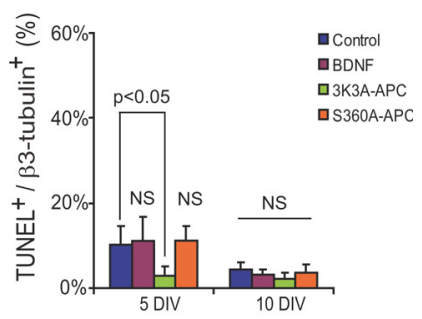

Figure 3. Human recombinant 3 K3A-APC stimulates neuronal differentiation of human NPCS. A, Representative confocal images of $\beta 3$-tubulin (green)/Hoechst (blue) double staining in human NPCs at 5 DIV (top) and 10 DIV (bottom). NPCs were treated with medium only (control, left), and BDNF (middle), or human 3 K3A-APC (right) at $1.4 \mathrm{~nm}$. B, Quantification of $\beta 3$-tubulin ${ }^{+} /$Hoechst $^{+}$cells at 5 and 10 DIV after treatment with medium only (control), BDNF, 3K3A-APC, or S360A-APC as in A. C, D, Representative confocal images of MAP2 (green)/Hoechst (blue) double staining in human NPCS $\left(\boldsymbol{C}\right.$ and quantification of $\mathrm{MAP2}^{+} /$Hoechst $^{+}$cells $(\boldsymbol{D})$ at 10 DIV after incubation with medium only (control), human 3K3A-APC, or S360A-APC at $1.4 \mathrm{~nm} . \boldsymbol{E}, \boldsymbol{F}$, High-magnification confocal imaging of MAP2 ${ }^{+}$neurites $($ red; $\boldsymbol{E})$ and total neurite length $(\boldsymbol{F})$ at 10 DIV after incubation with medium only, 3K3A-APC, or S360A-APC at 1.4 nM. G, Representative confocal images of $\beta 3$-tubulin (green)/TUNEL (red) double staining in human NPCs at 5 DIV (top) and 10 DIV (bottom). NPCs were treated with medium only (control, left), BDNF (middle), or 3K3A-APC (right) at $1.4 \mathrm{~nm}$. Arrows denote TUNEL ${ }^{+} / \beta 3$-tublin ${ }^{+}$cells. $\boldsymbol{H}$, Quantification of TUNEL ${ }^{+} / \beta 3$-tublin ${ }^{+}$cells at 5 and 10 DIV after treatment with medium (control), BDNF, 3K3A-APC, or S360A-APC as in $A$. Data are shown as mean \pm SEM, $n=3$ independent cultures; measurements in each culture were done in triplicate. Statistical significance was determined by one-way ANOVA followed by Tukey's range test. NS indicates not significant.

Western blot analyses. Whole cellular extracts and nuclear protein fractions were prepared and protein concentration was determined using Bradford protein assays (Bio-Rad). A total of $10-50 \mu \mathrm{g}$ of protein was analyzed by $10 \%$ SDS-PAGE and transferred to nitrocellulose membranes that were then blocked with 5\% nonfat milk in TBS (20 mM Tris, $\mathrm{pH}$ 8.0, $500 \mathrm{~mm} \mathrm{NaCl}, 0.1 \%$ Tween 20) for $1 \mathrm{~h}$. The membranes were incubated overnight with primary antibodies, washed with TBS, and incubated with a horseradish-peroxidase-conjugated secondary antibody for $1 \mathrm{~h}$. Immunoreactivity was detected using the ECL detection system (GE Healthcare).

Immunocytochemistry. The cells were fixed with $4 \%$ paraformaldehyde and stained for different cell markers using the antibodies listed above. 

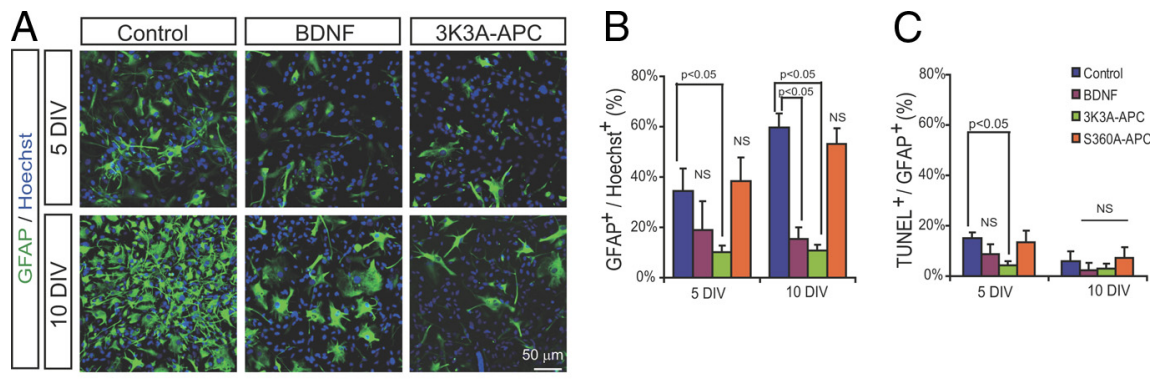

D
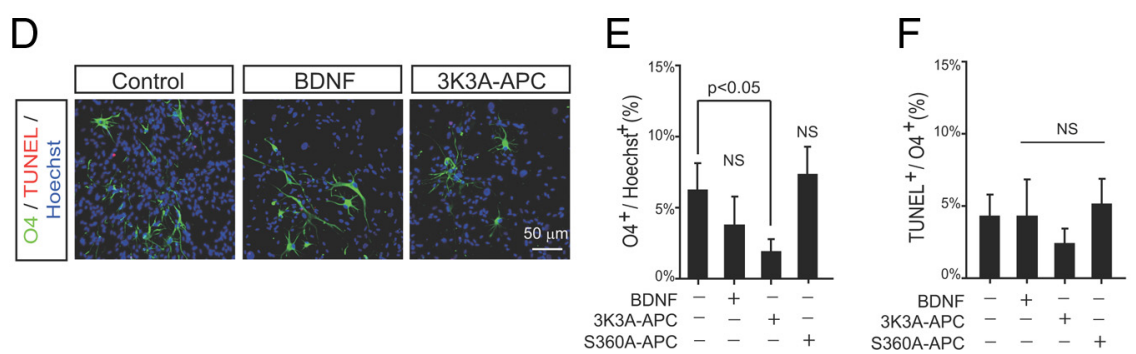

Figure 4. Human recombinant $3 \mathrm{~K} 3 \mathrm{~A}-\mathrm{APC}$ inhibits differentiation of astrocyte and oligodendrocyte lineages by human NPCs. $\boldsymbol{A}$, Representative confocal images of GFAP (green)/Hoechst (blue) double staining in human NPCs at 5 DIV and 10 DIV after treatment with medium only (control), BDNF, or 3K3A-APC at $1.4 \mathrm{~nm}$. B, Quantification of GFAP ${ }^{+}$(green)/Hoechst ${ }^{+}$(blue) cells at 5 and 10 DIV after treatment with medium (control), BDNF, 3K3A-APC, or S360A-APC as in A. C, Quantification of TUNEL ${ }^{+} /$GFAP $^{+}$cells at 5 and 10 DIV after medium (control), BDNF, 3K3A-APC, or S360A-APC as in A. D, E, Representative confocal images of oligodendrocyte marker 04 (green)/Hoechst (blue) double staining in human NPCS (D) and quantification of $04^{+} /$Hoechst $^{+}$cells $(\boldsymbol{E})$ at 10 DIV after incubation with vehicle, human 3K3A-APC, S360A-APC, or BDNF at $1.4 \mathrm{~nm}$. $\boldsymbol{F}$, Quantification of TUNEL ${ }^{+} / 04^{+}$cells after incubation with medium, human 3K3A-APC, S360A-APC, or BDNF at $1.4 \mathrm{~nm}$. Data are shown as mean $\pm \mathrm{SEM}, n=3$ independent cultures; measurements in each culture were done in triplicate. Statistical significance was determined by one-way ANOVA followed by Tukey's range test. NS indicates not significant.

The following fluorescence-conjugated secondary antibodies were used: Alexa Fluor 488-conjugated goat anti-mouse IgG (1:150; Invitrogen) to detect nestin and MAP2; Alexa Fluor 568-conjugated goat anti-rabbit IgG (1:150, Invitrogen) to detect Ki-67; and Alexa Fluor 568-conjugated goat anti-mouse IgG (1:150; Invitrogen) to detect $\beta 3$-tubulin, GFAP, and the oligodendrocyte marker O4. Images were obtained using a confocal Zeiss LSM 510 Axioscope 2 microscope or an inverted microscope (DMI6000 B; Leica Microsystems).

Statistical analysis. Data are presented as mean \pm SEM. One-way ANOVA followed by Tukey's post hoc test were used to determine statistically significant differences. $p<0.05$ was considered statistically significant.

\section{Results}

In all experiments described below, the effects of human $3 \mathrm{~K} 3 \mathrm{~A}-$ APC were studied in human NPCs derived from the telencephalic VZ/SVZ of fetal human brains taken from aborted fetuses at 15-22 weeks of gestational age as described previously (Wang et al., 2010).

\section{Human 3K3A-APC stimulates human NPC proliferation}

First, we determined whether human $3 \mathrm{~K} 3 \mathrm{~A}-\mathrm{APC}$ stimulated BrdU incorporation in human NPCs. Over a range of 0.5-5 nM, $3 \mathrm{~K} 3 \mathrm{~A}-\mathrm{APC}$ exerted a dose-dependent effect on BrdU incorporation based on an ELISA assay, with a maximal increase at $2 \mathrm{nM}$ and an $\mathrm{EC}_{50}$ value of $\sim 0.8 \mathrm{~nm}$ (Fig. $1 A$ ).

Next, we compared the mitogenic effects of $3 \mathrm{~K} 3 \mathrm{~A}-\mathrm{APC}$ with those of bFGF, a known mitogen for human subependymal progenitor cells (Pincus et al., 1998; Dayer et al., 2007). bFGF and $3 \mathrm{~K} 3 \mathrm{~A}-\mathrm{APC}$ were studied at a concentration of $1.4 \mathrm{nM}$, which is somewhat higher than the $\mathrm{EC}_{50}$ value for $3 \mathrm{~K} 3 \mathrm{~A}-\mathrm{APC}$ determined by ELISA (Fig. 1A). Both 3K3A-APC and bFGF exerted a comparable effect on $\mathrm{BrDU}$ incorporation and increased the percentage of cycling cells in the S phase by $89 \%$ and $79 \%$, respectively, within $48 \mathrm{~h}$ (Fig. $1 B-D)$. In contrast, S360A-APC, an enzymatically inactive analog of APC that lacks serine protease activity and the ability to activate PAR1 (Guo et al., 2009b; Zhong et al., 2009), did not stimulate NPC proliferation compared with vehicle (Fig. 1D). Cell cycle analysis based on the DNA content (7amino-actinomycin D) confirmed that the percentage of NPCs in the S phase was essentially doubled by $3 \mathrm{~K} 3 \mathrm{~A}-\mathrm{APC}$ or bFGF (Fig. 1E).

Double immunostaining for nestin, a marker of undifferentiated NPCs, and Ki67 , a marker of cells undergoing mitosis (Breunig et al., 2007), confirmed that the number of nestin $+/ \mathrm{Ki}-67+$ NPCs increased significantly in response to 3K3A-APC (1.4 nM), but not to the enzymatically inactive S360A-APC (Fig. $1 F, G$ ). The number of TUNEL ${ }^{+}$cells in a control group treated with the medium only (control) was very low (i.e., $3.6 \pm 1.1 \%$ ) and was not affected by bFGF or S360A-APC. 3K3AAPC exerted a modest anti-apoptotic effect, as determined by the reduction of $\mathrm{TUNEL}^{+} / \mathrm{Hoechst}^{+}$cells from $3.6 \pm 1.1 \%$ to $1.1 \pm 0.8 \%$ (Fig. $1 G$ ). At earlier time points ( $12 \mathrm{~h}$ ), the number of TUNEL + cells was negligible $(<3 \%)$ in all studied groups and was not significantly affected by either bFGF or 3K3A-APC. These experiments show that 3K3A-APC exerts a significant proliferative effect on human NPCs and that APC's enzymatic activity is needed for its effect on NPC proliferation.

\section{Human 3K3A-APC induces human NPCs migration}

A Boyden chamber assay was used to determine the migration of NPCs in the presence or absence of bFGF, 3K3A-APC, and S360A-APC at $1.4 \mathrm{~nm}$. bFGF and 3K3A-APC, but not S360AAPC, approximately doubled the migration index of NPCs compared with vehicle (Fig. 2A). We next examined the effects of $3 \mathrm{~K} 3 \mathrm{~A}-\mathrm{APC}$ on NPCs migration using the neurosphere migration assays on poly-L-ornithine-coated surface and in 3D Matrigel. In these assays, individual NPCs migrate radially away from the plated sphere, forming a rim of migrant cells around the sphere. bFGF, 3K3A-APC, and S360A-APC at $1.4 \mathrm{~nm}$ had no significant effect on the size of the spheres, as quantified by the neurosphere diameters within $16 \mathrm{~h}$ of plating (Fig. 2C,E). However, both bFGF and $3 \mathrm{~K} 3 \mathrm{~A}-\mathrm{APC}$, but not S360A-APC, at $1.4 \mathrm{~nm}$ significantly enhanced the migration of NPCs and increased the migration index compared with controls by 1.2 and 1.3 on a poly-L-ornithinecoated surface and 0.9 and 1.0 in 3D Matrigel, respectively, within $16 \mathrm{~h}$ after plating (Fig. $2 D, F$ ).

Human 3K3A-APC promotes differentiation of human NPCs NPCs were allowed to differentiate for 5 and 10 DIV in the presence or absence of BDNF, a growth factor known to strongly potentiate the maturation and survival of new neurons (Kirschenbaum and Goldman, 1995; Silva et al., 2009). To assess the relative effects of $\mathrm{BDNF}$ and $3 \mathrm{~K} 3 \mathrm{~A}-\mathrm{APC}$ on neuronal differentiation and maturation, first we determined the number of $\beta 3$ tubulin $^{+} /$Hoechst $^{+}$neuron-like cells (Breunig et al., 2007) and showed that BDNF and 3K3A-APC increased similarly the number 
of $\beta 3$-tubulin ${ }^{+}$cells (by 2.1 - and 2.3-fold at 5 DIV and by 2.3- and 2.7-fold at 10 DIV, respectively; Fig. $3 A, B)$. Using MAP2 as a second marker of neuronal differentiation (Breunig et al., 2007), we confirmed that 3K3A-APC, but not S360A-APC, increased significantly (by 3.1-fold) the number of MAP2 ${ }^{+} /$Hoechst $^{+}$cells (Fig. $3 C, D$ ), as well as their neuritic outgrowth (Fig. $3 E, F)$. At 5 $\mathrm{DIV}$, there was $10.3 \pm 4.3 \% \mathrm{TUNEL}^{+} / \beta$ tubulin ${ }^{+}$cells in the presence of medium only (control), indicating a moderate rate of spontaneous apoptosis under control conditions (Fig. 3G,H). BDNF and S360A-APC did not reduce the number of apopototic TUNEL $^{+} / \beta$-tubulin ${ }^{+}$cells; in contrast, $3 \mathrm{~K} 3 \mathrm{~A}-\mathrm{APC}$ reduced the number of apoptotic cells from $10.3 \pm 4.3 \%$ to $3.0 \pm 2.1 \%$ (Fig. $3 G, H$ ), which is consistent with its well known anti-apoptotic effects (Zlokovic and Griffin, 2011; Griffin et al., 2012). At 10 DIV, the rate of apoptosis was low in all groups $(<4 \%)$; no statistical differences were observed by altering the experimental conditions. These data suggest that under the present experimental conditions at 5 and 10 DIV, 3K3A-APC exerts a major effect on neuronal differentiation compared with its cell survival effect.

In contrast to significant effects of 3K3A-APC on neuronal differentiation of human NPCs at 5 and 10 DIV (Fig. 3), the percentage of $\beta 3$-tubulin ${ }^{+} /$Hoechst $^{+}$ cells at $2 \mathrm{DIV}$ in the presence of vehicle, 3K3A-APC, S360A-APC, and bFGF did not differ significantly and was relatively low (i.e., $6.9 \pm 0.7 \%, 7.8 \pm 1.2 \%, 6.6 \pm$ $1.0 \%$, and $5.9 \pm 0.6 \%$, respectively, mean \pm SEM, $n=3$ independent cultures; measurements in each culture were done in triplicate). The data indicate that neither $3 \mathrm{~K} 3 \mathrm{~A}-\mathrm{APC}$ nor bFGF had a significant effect on neuronal differentiation at an early stage at 2 DIV.

At 5 DIV, 3K3A-APC, but not S360A-APC or BDNF, inhibited potently the development of the $\mathrm{GFAP}^{+}$astrocyte lineage (Fig. $4 A, B)$. At $10 \mathrm{DIV}$, both $3 \mathrm{~K} 3 \mathrm{~A}-\mathrm{APC}$ and BDNF exhibited strong inhibitory effect on astrocyte differentiation. 3K3A-APC reduced the number of apoptotic GFAP ${ }^{+}$cells (Fig. 4C). The magnitude of 3K3A-APC's anti-apoptotic effect was substantially less pronounced than its inhibitory effect on astrocyte differentiation. 3K3A-APC, but not S360A-APC or BDNF, inhibited the development of the O4 oligodendrocyte lineage at $10 \mathrm{DIV}$ (Fig. $4 \mathrm{D}, \mathrm{E}$ ). The $\mathrm{O}^{+}$cell population represented a minor fraction of differentiated cells in the present assay. None of the studied proteins affected apoptosis of $\mathrm{O}^{+}$ cells (Fig. 4F). These experiments suggest that 3K3A-APC promotes differentiation and neuritogenesis by human NPCs and inhibits the development of astrocyte and oligodendrocyte lineages.

\section{Human 3K3A-APC's proneurogenic effects in human NPCs require PAR1, PAR3, and $S 1 P_{1}$}

In the present study, we have demonstrated (Figs. 1, 2, 3) that APC's enzymatic activity is required for $3 \mathrm{~K} 3 \mathrm{~A}-\mathrm{APC}$ proneurogenic activity, suggesting an involvement of the PARs in transducing the 3K3A-APC signal. To investigate whether PARs
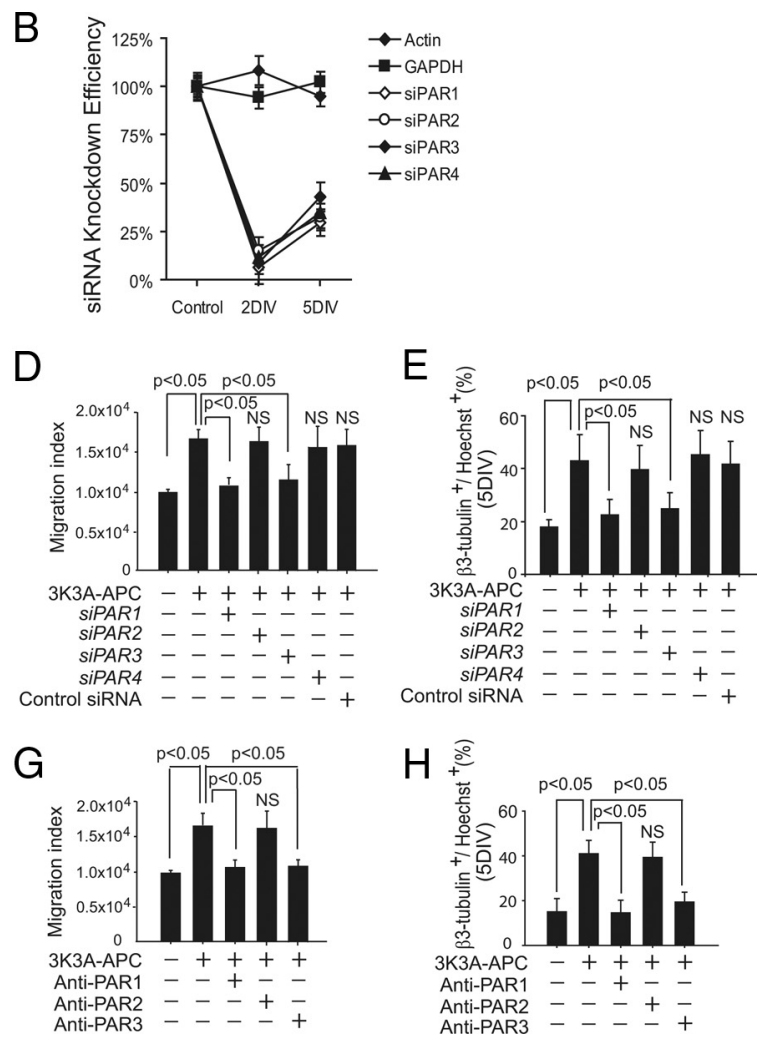

Figure 5. Effects of human recombinant $3 K 3 A-A P C$ on human NPC proliferation, migration and differentiation require PAR1 33 -tubulin ${ }^{+} /$Hoechst $^{+}$cells $(\boldsymbol{E})$ determined with and without human $3 \mathrm{~K} 3 \mathrm{~A}-\mathrm{APC}$ at $1.4 \mathrm{~nm}$ in the presence of PAR1, PAR2, PAR3 in culture. Data are shown as mean \pm SEM, $n=3$ independent cultures; measurements in each culture were done in triplicate. Statistical significance was determined by one-way ANOVA followed by Tukey's post hoc test. NS indicates not significant.

indeed mediate 3K3A-APC's effects on NPCs, we used siRNA to selectively and individually knock down the expression of each of the PARs (each achieving $~ 80-90 \%$ inhibition within 48 h; Fig. $5 A, B)$, and used the resultant knock-down cell populations to assess the effects of $3 \mathrm{~K} 3 \mathrm{~A}-\mathrm{APC}$ on BrdU incorporation and Boyden chamber migration at 2 DIV and neuronal differentiation by NPCs at 5 DIV. We found that PAR1 and PAR3 siRNAs, but not those targeting PAR2, PAR4, or control siRNA, abolished 3K3AAPC effects on each of these end points (Fig. $5 C-E$ ). We then corroborated these findings using cleavage-site-blocking PAR antibodies (Guo et al., 2009b), which inhibit the action of the respective PARs. As depicted in Figure $5 \mathrm{~F}-\mathrm{H}$, 3K3A-APCmediated neuronal mitogenesis and differentiation was inhibited by PAR1- and PAR3-specific antibodies, but not by anti-PAR2, confirming that $3 \mathrm{~K} 3 \mathrm{~A}-\mathrm{APC}$ promotes neurogenesis from NPCs via PAR1 and PAR3.

APC has been shown to strengthen endothelial barriers via PAR1-mediated activation of sphingosine kinase 1 (Sphk-1), which generates sphingosine-1-phosphate (S1P), a biologically active sphingolipid that signals via $\mathrm{S} 1 \mathrm{P}$ receptors (Feistritzer and Riewald, 2005; Finigan et al., 2005). All five S1P receptor subtypes, $\mathrm{S}_{\mathrm{PPR}}, \mathrm{S}_{1} \mathrm{PR}_{2}, \mathrm{~S}_{\mathrm{PR}}, \mathrm{S}_{3} \mathrm{PR}_{4}$, and $\mathrm{S} 1 \mathrm{PR}_{5}$, are expressed in NPCs (Harada et al., 2004). Activation of S1PR has been shown to stimulate the proliferation and migration of NPCs (Kimura et 
A

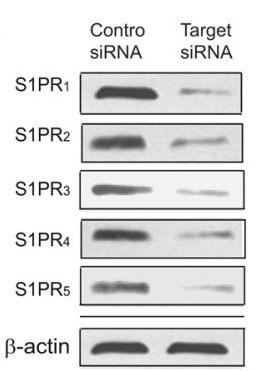

C

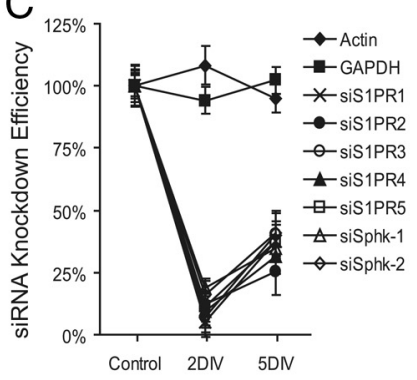

D

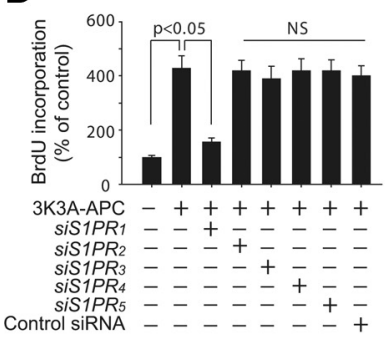

G

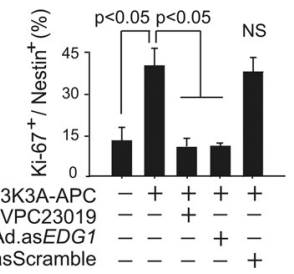

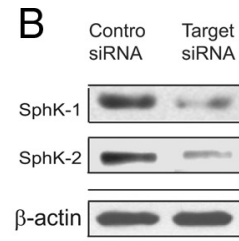

E

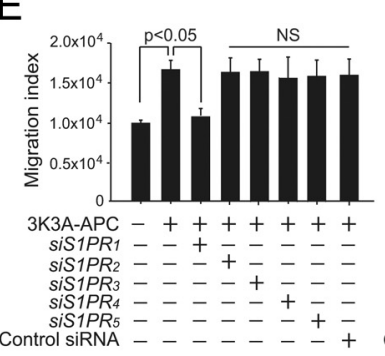

$\mathrm{H}$

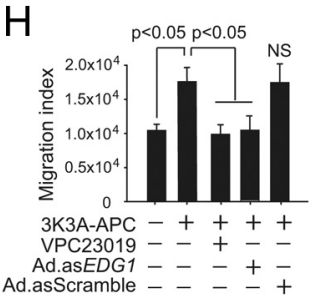

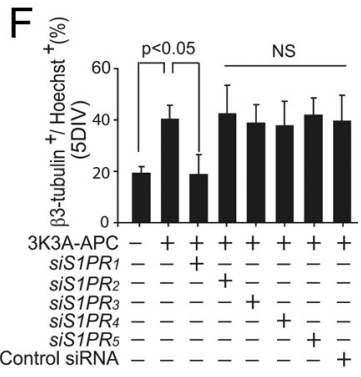

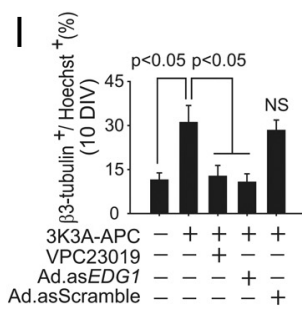

Figure 6. Effects of human recombinant $3 \mathrm{~K} 3 \mathrm{~A}-\mathrm{APC}$ on human NPC proliferation, migration, and differentiation requires $S 1 P R_{1}$. $\boldsymbol{A}$, Western blots for $\mathrm{S}_{1} \mathrm{P}_{1}, \mathrm{~S}_{\mathrm{P}}, \mathrm{S}_{2} \mathrm{P}_{3}, \mathrm{~S}_{1} \mathrm{P}_{4}$, and $\mathrm{S}_{\mathrm{P}}$ in whole-cell extracts from human NPC $48 \mathrm{~h}$ after transfection with siRNA oligonucleotides targeting $S 1 \mathrm{PR}_{1}, \mathrm{~S}_{\mathrm{PR}}, \mathrm{S}_{\mathrm{PR}}, \mathrm{S} 1 \mathrm{PR}_{4}$, and $\mathrm{S} 1 \mathrm{PR}_{5}$. Each panel is representative of three independent experiments. $\beta$-actin was used as a control for protein loading $(\boldsymbol{B})$. Western blots for Sphk-1, Sphk-2 in whole-cell extracts from human NPCS $48 \mathrm{~h}$ after transfection with siRNA oligonucleotides targeting Sphk-1 and Sphk-2. C, The knock-down efficiency in the NPCS examined with quantitative PCR of S1P $, S_{1} P_{2}, S 1 P_{3}, S 1 P_{4}$, and S1P 5 at 2 and 5 DIV; GAPDH and $\beta$-actin were used as controls. $\boldsymbol{D}-\boldsymbol{F}$, BrdU incorporation $(\boldsymbol{D})$, migration index $(\boldsymbol{E})$, and $\beta 3$-tubulin ${ }^{+} / \mathrm{H}_{\text {oechst }}{ }^{+}$cells $(\boldsymbol{F})$ determined with and without $3 \mathrm{~K} 3 \mathrm{~A}-\mathrm{APC}$ at 1.4 $\mathrm{nm}$ in the presence of $S 1 P R_{1}, S 1 P R_{2}, S 1 P R_{3}, S 1 P R_{4}$, and S1PR , inhibition by siRNA silencing, or control siRNA after $48 \mathrm{~h}(\boldsymbol{D}, \boldsymbol{E})$ and $5 \mathrm{~d}$ $(\boldsymbol{F})$ in culture. $(\boldsymbol{G}-\boldsymbol{I})$ Quantification of nestin ${ }^{+} / \mathrm{Ki}-67^{+}$cells $(\boldsymbol{G})$, $\operatorname{migration}$ index $(\boldsymbol{H})$, and $\beta 3$-tubulin ${ }^{+} / \mathrm{H}_{\text {oechst }}{ }^{+}$cells $(\boldsymbol{I})$ determined with and without $3 \mathrm{~K} 3 \mathrm{~A}-\mathrm{APC}$ at $2 \mathrm{~nm}$ in the presence and absence VPC23019 (10 $\mu \mathrm{m}$, a chemical antagonist of $S 1 P R_{1}$ and $\mathrm{S}_{\mathrm{PR}}$ antagonist) or transduced with Ad.asEDG1 or Ad.asScramble, after $48 \mathrm{~h}(\boldsymbol{G}, \boldsymbol{H})$ and $5 \mathrm{~d}(\boldsymbol{I})$ in culture. Data are shown as mean \pm SEM, $n=3$ independent cultures; measurements in each culture were done in triplicate. Statistical significance was determined by one-way ANOVA followed by Tukey's post hoc test. NS indicates not significant.

al., 2007). To address whether S1P receptors participate in 3K3AAPC-mediated neurogenesis by human NPCs, we inhibited each of the five S1P receptors by siRNA silencing (each achieving 75$90 \%$ inhibition within 48 h; Fig. $6 A, B)$. We then studied the effects of 3K3A-APC on BrdU incorporation in the S1PR knockdown NPCs and on the differentiation of NPCs into $\beta 3$-tubulin ${ }^{+}$ cells using the same experimental conditions that we had used in untransduced NPCs. We found that $\mathrm{S}_{\mathrm{PR}}$ inhibition, but not $\mathrm{S}_{\mathrm{PR}}, \mathrm{S}_{2} \mathrm{PR}_{3}, \mathrm{~S} 1 \mathrm{PR}_{4}$, and $\mathrm{S} 1 \mathrm{PR}_{5}$ or control siRNA, abrogated $3 \mathrm{~K} 3 \mathrm{~A}-\mathrm{APC}$ 's effects on NPC proliferation and differentiation (Fig. $6 C-E$ ). These data indicate that $S 1 \mathrm{PR}_{1}$ activation is required for 3K3A-APC's effects on NPCs. In support of these findings, we next showed that VPC 239019, a chemical antagonist of S1PR and $\mathrm{S}_{1 \mathrm{PR}_{3}}$ (Davis et al., 2005), and Ad.asEDG1, an adenoviral vector expressing the antisense oligonucleotide directed against $\mathrm{S}_{\mathrm{PPR}}$, both abolished 3K3A-APC's effects on NPCs (Fig. 6F-H). These data thus confirmed that $\mathrm{S}_{\mathrm{PR}}$ is required for $3 \mathrm{~K} 3 \mathrm{~A}-\mathrm{APC}$ mediated support of neural progenitor mitogenesis and neuronal differentiation.
Human 3K3A-APC activates the PI3K/ Akt pathway, which requires PAR1, PAR3, and $\mathrm{S}_{1} \mathrm{PR}_{1}$ Activation of S1PR leads to PI3K/Akt signaling (Morales-Ruiz et al., 2001), which has been shown to be involved in the proliferation, differentiation, and survival of NPCs (Wang et al., 2005; Otaegi et al., 2006; Peltier et al., 2007). To investigate whether 3K3A-APC exerts its effects on NPCs through S1PR 1 -initiated PI3K/Akt signaling, we first examined the direct effect of $3 \mathrm{~K} 3 \mathrm{~A}-\mathrm{APC}$ on Akt phosphorylation. Treatment of NPCs with $3 \mathrm{~K} 3 \mathrm{~A}-$ APC, but not S360A-APC, increased phosphorylated-Akt levels by 2.4-fold relative to vehicle-treated controls when assessed at 3 h (Fig. 7A). LY294002, a PI3K inhibitor, blocked 3K3A-APC-mediated phosphorylation of Akt (Fig. 7A).

Inhibition of PAR1 and PAR3 by siRNA silencing, but not that of either PAR2 or PAR4 (data not shown) or of a control siRNA, blocked 3K3A-APC-induced Akt phosphorylation (Fig. 7B). Similarly, silencing of $S 1 \mathrm{PR}_{1}$, but not $S 1 \mathrm{PR}_{2}, \mathrm{~S}_{\mathrm{PR}}, \mathrm{S}_{1 \mathrm{PR}}$, $\mathrm{S}_{\mathrm{PPR}}$, or control siRNA, blocked $3 \mathrm{~K} 3 \mathrm{~A}-$ APC-induced Akt phosphorylation (Fig. 7C). In addition, siRNA inhibition of Sphk-1, but not Sphk-2 (Fig. 7D,E), also blocked 3K3A-APC-induced Akt phosphorylation (Fig. 7D). These experiments demonstrated that Akt activation by $3 \mathrm{~K} 3 \mathrm{~A}-$ APC in NPCs requires PAR1, PAR3, and the activation of $S 1 P R_{1}$.

To confirm that Akt activation plays a key role in 3K3A-APC-mediated neuronal production, NPC cultures were transduced with a recombinant adenovirus expressing a kinase-defective dominantnegative Akt mutant (Ad.Akt ${ }^{k 179}$; Guo et al., 2011) or GFP. The transduction efficiency was $\sim 70 \%$ as determined by GFP fluorescence (data not shown). Ad. $A k t^{k 179 A}$, but not control Ad.GFP, blocked the 3K3A-APC-associated increment of neuronal production (Fig. $7 F-H$ ), suggesting that $3 \mathrm{~K} 3 \mathrm{~A}-\mathrm{APC}-$ mediated neuronal production requires Akt-mediated signaling.

The neurogenic potential of NPCs in culture may vary with age or passage and "young," lower passage NPCs are more neurogenic than the "old," higher passage NPCs (Okada et al., 2008, Wang et al., 2010; Sakayori et al., 2011). To address whether $3 \mathrm{~K} 3 \mathrm{~A}-\mathrm{APC}$ exerts the neurogenic potential in older passage NPCs, we compared the effects of $3 \mathrm{~K} 3 \mathrm{~A}$-APC on neuronal differentiation in passage 2 and passage 6 NPCs. As shown in Figure $7 \mathrm{H}$, passage $6 \mathrm{NPCs}$ at $10 \mathrm{DIV}$ generated fewer neurons than passage 2 NPCs (i.e., $7.3 \pm 0.8 \%$ compared with $10.8 \pm 2.3 \%, p<$ $0.05)$, which is consistent with previous reports. However, $3 \mathrm{~K} 3 \mathrm{~A}-$ APC had a comparable effect on neuronal differentiation in passage 2 and 6 NPCs, as indicated by the similar 2.1-fold and 2.0 -fold increases in the number of $\beta 3$-tubulin ${ }^{+}$neurons, respectively. The 3K3A-APC effect in passage 6 NPCs was inhibited by the kinase-deficient dominant-negative Akt mutant $\left(\right.$ Ad. $\left.A k t^{k 179}\right)$. These data suggest that $3 \mathrm{~K} 3 \mathrm{~A}-\mathrm{APC}$ can promote 
neuronal differentiation in higherpassage human NPCs by modulating the Akt pathway.

\section{Discussion}

This study demonstrates that $3 \mathrm{~K} 3 \mathrm{~A}-\mathrm{APC}$ enhances neuronal production preferentially by primary human NPCs derived from fetal human SVZ. We also show that 3K3A-APC inhibits the development of astrocyte and oligodendrocyte lineages from human NPCs. 3K3A-APC's proneurogenic effects are similar to these of BDNF, which has been shown to promote neuronal differentiation of cultured NPCs (Goldman et al., 1997) while suppressing astrocyte differentiation (Nakamura et al., 2011). Because inflammatory mediators after CNS injury or diseases and NPCs transplantation promote astrogliosis but inhibit neurogenesis (Sahni and Kessler, 2010; Robel et al., 2011), the promoting effect on neuronal differentiation but inhibiting effect on astroglial differentiation and inflammation by $3 \mathrm{~K} 3 \mathrm{~A}-\mathrm{APC}$ would favorably support a 3K3A-APC-related clinical trial for CNS repair.

Our siRNA studies revealed that human recombinant 3K3A-APC-mediated neuronal production by human NPCs requires the PAR1, PAR3, and $\mathrm{S}_{1} \mathrm{PR}_{1}$ transmembrane receptors. Multiple studies have demonstrated that the beneficial effects of APC require PAR1 in most cell types (Zlokovic and Griffin, 2011), whereas its effects in murine neurons require PAR1 and PAR3 cooperation (Guo et al., 2004; Liu et al., 2004; Guo et al., 2009b; Zhong et al., 2009). In primary human endothelial cells derived from umbilical vein or pulmonary artery, human wild-type APC has been shown to transactivate $\mathrm{S}_{1} \mathrm{PR}_{1}$ via ECPR and PAR1, which in turn activates Sphk-1, leading to cytoskeletal rearrangements and enhancement of endothelial barriers (Feistritzer and Riewald, 2005; Finigan et al., 2005). Conversely, activation of $\mathrm{S}_{\mathrm{PR}}$, has been shown to induce proliferation, migration, and morphological changes in NPCs (Harada et al., 2004; Kimura et al., 2007). The present study shows that PAR1 and PAR3 inhibition, as well as Sphk-1 and $\mathrm{S1PR}_{1}$ inhibition by siRNA silencing, blocks 3K3A-APC-mediated neurogenesis, thus implying that PAR1 and PAR3 might cross-activate $\mathrm{S}_{1} \mathrm{PR}_{1}$, which is required for 3K3A-APC's neurogenic effects.

$\mathrm{S}_{1} \mathrm{PR}_{1}$ activation results in PI3K/Akt signaling, which has been found to regulate the proliferation, survival, and differentiation of NPCs (Wang et al., 2005; Otaegi et al., 2006; Peltier et al., 2007). In the present study, we show that inhibition of $\mathrm{S}_{\mathrm{PPR}}$ and Sphk-1 results in loss of 3K3A-APC-mediated activation of Akt, confirming the importance of S1PR ${ }_{1}$ activation for APC's actions. In addition, inhibition of PAR1 and PAR3 also resulted in loss of Akt activation by $3 \mathrm{~K} 3 \mathrm{~A}-\mathrm{APC}$, further suggesting that co-
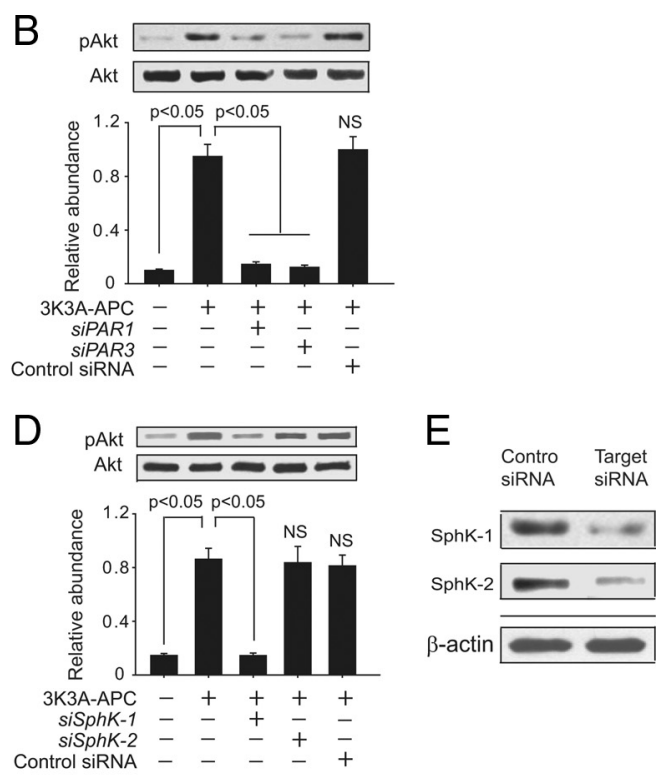

Figure 7. Activation of the PI3K/Akt pathway in human NPCs by human recombinant 3K3A-APC requires PAR1, PAR3, and $\mathrm{S}_{\mathrm{PPR}}$. A, Western blots for pAkt (Ser473) and total Akt in whole-cell extracts from human NPCs $3 \mathrm{~h}$ after human 3K3A-APC Akt. $\boldsymbol{B}$, Western blots for pAkt (Ser473) and total Akt in whole-cell extracts were determined $3 \mathrm{~h}$ after 3K3A-APC or vehicle Intensity of pAkt signal determined by scanning densitometry and normalized to total Akt. C, Western blots for pAkt (Ser473) and total Akt in whole-cell extracts from human NPCs $3 \mathrm{~h}$ after 3K3A-APC or vehicle treatment with or without siRNA-mediated densitometry and normalized to total Akt. D, Western blots for pAkt (Ser473) and total Akt in whole-cell extracts from human NPCs $3 \mathrm{~h}$ after 3K3A-APC treatment with or without siRNA-mediated inhibition of Sphk-1 and Sphk-2 or control siRNAs. The intensity of

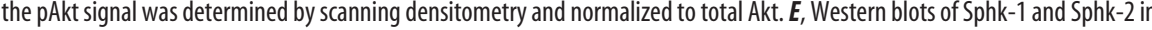
whole-cell extracts from human NPCs $48 \mathrm{~h}$ after transfection with siRNA oligonucleotides targeting Sphk-1 and Sphk-2. F, BrdU incorporation by human NPCs transduced with Ad.Akt ${ }^{k 179 A}$ or Ad.GFP and treated with 3K3A-APC or vehicle for 2 d. G, Migration of suspended NPCs transduced with Ad. $A k^{k 179 A}$ or Ad.GFP and treated with $3 \mathrm{k} 3 \mathrm{~A}-\mathrm{APC}$ of vehicle for $5 \mathrm{~h}$. $\boldsymbol{H}$, Differentiation of passage 2 and passage 6 NPCs transduced with Ad.Akt ${ }^{k 179 A}$ or Ad.GFP into $\beta 3$-tubulin ${ }^{+}$cells after 3K3A-APC or vehicle at 10 DIV. In all studies, human 3K3A-APC was used at 2 nm. Data are shown as mean $\pm \mathrm{SEM}, n=3$ independent cultures in triplicate. Statistical significance was determined by one-way ANOVA followed by Tukey's post hoc test. NS indicates not significant.

operation of PAR1 and PAR3 after 3K3A-APC stimulation might be required for $\mathrm{S}_{1} \mathrm{PR}_{1}$ transactivation in NPCs, similar to results shown in endothelial cells for endothelial protein $\mathrm{C}$ receptor and PAR1 (Feistritzer and Riewald, 2005; Finigan et al., 2005). That Akt is a key signal intermediate for 3K3A-APC-induced neuronal mitogenesis and differentiation has been demonstrated by the loss of 3K3A-APC's effects in NPCs transfected with a kinaseinactive dominant-negative Akt mutant.

Our data suggest that APC supports different stages during neuronal production from human fetal NPCs, including proliferation of NPCs, migration of differentiating NPCs/neuroblasts, and differentiation of NPCs to neuronal cells. However, the exact intracellular signal transduction cascade(s) downstream to Akt that mediate 3K3A-APC effects during different stages of neurogenesis remain elusive and should be investigated by future stud- 
ies. For example, Akt activation has been shown to inactivate glycogen synthase kinase $3 \beta$ (Cross et al., 1995), allowing nuclear translocation of $\beta$-catenin, which in turn may promote the mitotic expansion of NPCs (Hirabayashi et al., 2004; Mao et al., 2009). In addition, phosphorylation of the mammalian target of rapamycin by Akt has been shown to regulate neuronal development and differentiation, dendritic growth and branching in particular (Jossin and Goffinet, 2007; Saxe et al., 2007; Kim et al., 2009). Whether APC treatment can activate these downstream Akt pathways and/or trigger the additional Akt downstream pathways that are required for different stages of neurogenesis is presently unknown.

Apoptosis of newborn neurons during both neurodevelopment and adult neurogenesis has been demonstrated repeatedly (Sierra et al., 2010; Kim and Sun, 2011). Consistent with its well demonstrated anti-apoptotic effects in different cell types, including neurons (Zlokovic and Griffin, 2011), 3K3A-APC exerted modest anti-apoptotic effects during neuronal mitogenesis and differentiation. The magnitude of 3K3A-APC's cellprotective effects in the present assays was substantially lower compared with its effects on neuronal production. It is possible, however, that in vivo 3K3A-APC anti-apoptotic effects might contribute importantly to enhancing the survival of transplanted NPCs, which will further amplify 3K3A-APC-mediated neuronal production. Determining the effects of $3 \mathrm{~K} 3 \mathrm{~A}-\mathrm{APC}$ on apoptosis versus proliferation, migration, and differentiation of human NPCs in an animal model of injury (e.g., ischemic stroke) should be pursued by future studies. However, these in vivo studies are beyond the scope of the present study, which provides the kinds of novel mechanistic insights relevant to 3K3A-APC therapy and human NPCs.

Our results support that APC therapy for neuroregeneration could have a translational potential in humans, encouraging further studies to establish the relevance of the APC cascade for embryonic and adult neurogenesis in vivo. For example, APC treatment might find potential applications in brain developmental disorders such as some forms of human developmental microcephaly associated with abnormalities in cellular production and brain failure to generate the proper number of neurons that determine brain size. Moreover, some neurodegenerative disorders of the aging brain, such as Alzheimer's disease and Parkinson's disease, might potentially benefit from pharmacologically enhanced neurogenesis by APC, particularly as the cellsignaling APC analogs can cross the blood-brain barrier (Deane et al., 2009) and exert potent beneficial effects within the neurovascular unit (e.g., direct neuronal and vascular protection and anti-inflammatory activity; Zlokovic and Griffin, 2011; Zlokovic, 2011) that will support neurogenesis and survival of newly born neurons. In addition, the present results suggest that APC-based monotherapy might enhance postischemic and posttraumatic subependymal neurogenesis in humans similarly to that reported in rodent models of stroke (Thiyagarajan et al., 2008) or traumatic (Petraglia et al., 2010) brain injury. Finally, the APC approach could also enhance cell therapy with exogenous human NPCs that may be of interest for several ongoing clinical trials with exogenous NPCs for stroke (clinical trial identifier NCT01287936, SanBio), spinal cord injury (clinical trial identifier NCT01321333, StemCells), and/or neurological disorders such as Parkinson's disease (clinical trial identifier NCT01329926, NeuroGeneration).

In summary, these experiments indicate that APC signaling, as triggered here by its recombinant analog $3 \mathrm{~K} 3 \mathrm{~A}-\mathrm{APC}$, promotes neuronal production and differentiation specifically by human NPCs via PAR1-PAR3-S1PR 1 -Akt-mediated signaling.
The proneurogenic effects of 3K3A-APC shown here in human NPCs suggest the potential for APC-based clinical therapeutics for both development and repair in the human CNS.

\section{References}

Breunig JJ, Arellano JI, Macklis JD, Rakic P (2007) Everything that glitters isn't gold: a critical review of postnatal neural precursor analyses. Cell Stem Cell 1:612-627. CrossRef Medline

Cheng T, Petraglia AL, Li Z, Thiyagarajan M, Zhong Z, Wu Z, Liu D, Maggirwar SB, Deane R, Fernández JA, LaRue B, Griffin JH, Chopp M, Zlokovic BV (2006) Activated protein C inhibits tissue plasminogen activator-induced brain hemorrhage. Nat Med 12:1278-1285. CrossRef Medline

Cross DA, Alessi DR, Cohen P, Andjelkovich M, Hemmings BA (1995) Inhibition of glycogen synthase kinase- 3 by insulin mediated by protein kinase B. Nature 378:785-789. CrossRef Medline

Davis MD, Clemens JJ, Macdonald TL, Lynch KR (2005) Sphingosine 1-phosphate analogs as receptor antagonists. J Biol Chem 280:9833-9841. CrossRef Medline

Dayer AG, Jenny B, Sauvain MO, Potter G, Salmon P, Zgraggen E, Kanemitsu M, Gascon E, Sizonenko S, Trono D, Kiss JZ (2007) Expression of FGF-2 in neural progenitor cells enhances their potential for cellular brain repair in the rodent cortex. Brain 130:2962-2976. CrossRef Medline

Deane R, LaRue B, Sagare AP, Castellino FJ, Zhong Z, Zlokovic BV (2009) Endothelial protein $C$ receptor-assisted transport of activated protein $\mathrm{C}$ across the mouse blood-brain barrier. J Cereb Blood Flow Metab 29:25-33. CrossRef Medline

Durbec P, Franceschini I, Lazarini F, Dubois-Dalcq M (2008) In vitro migration assays of neural stem cells. In: Neural stem cells (Weiner L, ed), pp 213-225. New York: Humana.

Feistritzer C, Riewald M (2005) Endothelial barrier protection by activated protein C through PAR1-dependent sphingosine 1-phosphate receptor-1 crossactivation. Blood 105:3178-3184. CrossRef Medline

Finigan JH, Dudek SM, Singleton PA, Chiang ET, Jacobson JR, Camp SM, Ye SQ, Garcia JG (2005) Activated protein C mediates novel lung endothelial barrier enhancement: role of sphingosine 1-phosphate receptor transactivation. J Biol Chem 280:17286-17293. CrossRef Medline

Gale AJ, Tsavaler A, Griffin JH (2002) Molecular characterization of an extended binding site for coagulation factor $\mathrm{Va}$ in the positive exosite of activated protein C. J Biol Chem 277:28836-28840. CrossRef Medline

Goldman SA, Kirschenbaum B, Harrison-Restelli C, Thaler HT (1997) Neuronal precursors of the adult rat subependymal zone persist into senescence, with no decline in spatial extent or response to BDNF. J Neurobiol 32:554-566. CrossRef Medline

Griffin JH, Zlokovic BV, Mosnier LO (2012) Protein C anticoagulant and cytoprotective pathways. Int J Hematol 95:333-345. CrossRef Medline

Guo H, Liu D, Gelbard H, Cheng T, Insalaco R, Fernández JA, Griffin JH, Zlokovic BV (2004) Activated protein C prevents neuronal apoptosis via protease activated receptors 1 and 3. Neuron 41:563-572. CrossRef Medline

Guo H, Wang Y, Singh I, Liu D, Fernández JA, Griffin JH, Chow N, Zlokovic BV (2009a) Species-dependent neuroprotection by activated protein C mutants with reduced anticoagulant activity. J Neurochem 109:116-124. CrossRef Medline

Guo H, Singh I, Wang Y, Deane R, Barrett T, Fernández JA, Chow N, Griffin JH, Zlokovic BV (2009b) Neuroprotective activities of activated protein C mutant with reduced anticoagulant activity. Eur J Neurosci 29:1119 1130. CrossRef Medline

Guo H, Barrett TM, Zhong Z, Fernández JA, Griffin JH, Freeman RS, Zlokovic BV (2011) Protein S blocks the extrinsic apoptotic cascade in tissue plasminogen activator/N-methyl D-aspartate-treated neurons via Tyro3Akt-FKHRL1 signaling pathway. Mol Neurodegener 6:13. CrossRef Medline

Harada J, Foley M, Moskowitz MA, Waeber C (2004) Sphingosine-1phosphate induces proliferation and morphological changes of neural progenitor cells. J Neurochem 88:1026-1039. CrossRef Medline

Hirabayashi $\mathrm{Y}$, Itoh $\mathrm{Y}$, Tabata H, Nakajima K, Akiyama T, Masuyama N, Gotoh Y (2004) The Wnt/beta-catenin pathway directs neuronal differentiation of cortical neural precursor cells. Development 131:2791-2801. CrossRef Medline

Jossin Y, Goffinet AM (2007) Reelin signals through phosphatidylinositol 
3-kinase and Akt to control cortical development and through mTor to regulate dendritic growth. Mol Cell Biol 27:7113-7124. CrossRef Medline Karumbayaram S, Novitch BG, Patterson M, Umbach JA, Richter L, Lindgren A, Conway AE, Clark AT, Goldman SA, Plath K, Wiedau-Pazos M, Kornblum HI, Lowry WE (2009) Directed differentiation of human-induced pluripotent stem cells generates active motor neurons. Stem Cells 27:806811. CrossRef Medline

Kerschen EJ, Fernandez JA, Cooley BC, Yang XV, Sood R, Mosnier LO, Castellino FJ, Mackman N, Griffin JH, Weiler H (2007) Endotoxemia and sepsis mortality reduction by non-anticoagulant activated protein C. J Exp Med 204:2439-2448. CrossRef Medline

Keyoung, Fau. RN, Goldman SA (2001) High-yield selection and extraction of two promoter-defined phenotypes of neural stem cells from the fetal human brain.

Kim JY, Duan X, Liu CY, Jang MH, Guo JU, Pow-anpongkul N, Kang E, Song H, Ming GL (2009) DISC1 regulates new neuron development in the adult brain via modulation of AKT-mTOR signaling through KIAA1212. Neuron 63:761-773. CrossRef Medline

Kim WR, Sun W (2011) Programmed cell death during postnatal development of the rodent nervous system. Dev Growth Differ 53:225-235. CrossRef Medline

Kimura A, Ohmori T, Ohkawa R, Madoiwa S, Mimuro J, Murakami T, Kobayashi E, Hoshino Y, Yatomi Y, Sakata Y (2007) Essential roles of sphingosine 1-phosphate/S1P1 receptor axis in the migration of neural stem cells toward a site of spinal cord injury. Stem Cells 25:115-124. CrossRef Medline

Kirschenbaum B, Goldman SA (1995) Brain-derived neurotrophic factor promotes the survival of neurons arising from the adult rat forebrain subependymal zone. Proc Natl Acad Sci U S A 92:210-214. CrossRef Medline

Kong H, Fan Y, Xie J, Ding J, Sha L, Shi X, Sun X, Hu G (2008) AQP4 knockout impairs proliferation, migration and neuronal differentiation of adult neural stem cells. J Cell Sci 121:4029-4036. CrossRef Medline

Liu D, Cheng T, Guo H, Fernández JA, Griffin JH, Song X, Zlokovic BV (2004) Tissue plasminogen activator neurovascular toxicity is controlled by activated protein C. Nat Med 10:1379-1383. CrossRef Medline

Mao Y, Ge X, Frank CL, Madison JM, Koehler AN, Doud MK, Tassa C, Berry EM, Soda T, Singh KK, Biechele T, Petryshen TL, Moon RT, Haggarty SJ, Tsai LH (2009) Disrupted in schizophrenia 1 regulates neuronal progenitor proliferation via modulation of GSK3beta/beta-catenin signaling. Cell 136:1017-1031. CrossRef Medline

Morales-Ruiz M, Lee MJ, Zöllner S, Gratton JP, Scotland R, Shiojima I, Walsh K, Hla T, Sessa WC (2001) Sphingosine 1-phosphate activates Akt, nitric oxide production, and chemotaxis through a Gi protein/phosphoinositide 3-kinase pathway in endothelial cells. J Biol Chem 276:19672-19677. CrossRef Medline

Mosnier LO, Gale AJ, Yegneswaran S, Griffin JH (2004) Activated protein C variants with normal cytoprotective but reduced anticoagulant activity. Blood 104:1740-1744. CrossRef Medline

Mosnier LO, Zlokovic BV, Griffin JH (2007) The cytoprotective protein C pathway. Blood 109:3161-3172. CrossRef Medline

Nakamura M, Tsuji O, Bregman BS, Toyama Y, Okano H (2011) Mimicking the neurotrophic factor profile of embryonic spinal cord controls the differentiation potential of spinal progenitors into neuronal cells. PLoS One 6:e20717. CrossRef Medline

Okada Y, Matsumoto A, Shimazaki T, Enoki R, Koizumi A, Ishii S, Itoyama Y, Sobue G, Okano H (2008) Spatiotemporal recapitulation of central nervous system development by murine embryonic stem cell-derived neural stem/progenitor cells. Stem Cells 26:3086-3098. CrossRef Medline

Otaegi G, Yusta-Boyo MJ, Vergaño-Vera E, Méndez-Gómez HR, Carrera AC, Abad JL, González M, de la Rosa EJ, Vicario-Abejón C, de Pablo F (2006) Modulation of the PI 3-kinase-Akt signalling pathway by IGF-I and PTEN regulates the differentiation of neural stem/precursor cells. J Cell Sci 119: 2739-2748. CrossRef Medline

Peltier J, O'Neill A, Schaffer DV (2007) PI3K/Akt and CREB regulate adult neural hippocampal progenitor proliferation and differentiation. Dev Neurobiol 67:1348-1361. CrossRef Medline

Petraglia AL, Marky AH, Walker C, Thiyagarajan M, Zlokovic BV (2010) Activated protein $\mathrm{C}$ is neuroprotective and mediates new blood vessel formation and neurogenesis after controlled cortical impact. Neurosurgery 66:165-171; discussion 171-172. CrossRef Medline

Pincus DW, Keyoung HM, Harrison-Restelli C, Goodman RR, Fraser RA,
Edgar M, Sakakibara S, Okano H, Nedergaard M, Goldman SA (1998) Fibroblast growth factor-2/brain-derived neurotrophic factor-associated maturation of new neurons generated from adult human subependymal cells. Ann Neurol 43:576-585. CrossRef Medline

Riewald M, Petrovan RJ, Donner A, Mueller BM, Ruf W (2002) Activation of endothelial cell protease activated receptor 1 by the protein C pathway. Science 296:1880-1882. CrossRef Medline

Robel S, Berninger B, Götz M (2011) The stem cell potential of glia: lessons from reactive gliosis. Nat Rev Neurosci 12:88-104. CrossRef Medline

Robey E, Chang D, Itano A, Cado D, Alexander H, Lans D, Weinmaster G, Salmon P (1996) An activated form of Notch influences the choice between CD4 and CD8 T cell lineages. Cell 87:483-492. CrossRef Medline

Sahni V, Kessler JA (2010) Stem cell therapies for spinal cord injury. Nat Rev Neurol 6:363-372. CrossRef Medline

Sakayori N, Maekawa M, Numayama-Tsuruta K, Katura T, Moriya T, Osumi N (2011) Distinctive effects of arachidonic acid and docosahexaenoic acid on neural stem/progenitor cells. Genes Cells 16:778-790. CrossRef Medline

Saxe JP, Wu H, Kelly TK, Phelps ME, Sun YE, Kornblum HI, Huang J (2007) A phenotypic small-molecule screen identifies an orphan ligand-receptor pair that regulates neural stem cell differentiation. Chem Biol 14:1019-1030. CrossRef Medline

Schaphorst KL, Chiang E, Jacobs KN, Zaiman A, Natarajan V, Wigley F, Garcia JG (2003) Role of sphingosine-1 phosphate in the enhancement of endothelial barrier integrity by platelet-released products. Am J Physiol Lung Cell Mol Physiol 285:258-267. CrossRef Medline

Sierra A, Encinas JM, Deudero JJ, Chancey JH, Enikolopov G, OverstreetWadiche LS, Tsirka SE, Maletic-Savatic M (2010) Microglia shape adult hippocampal neurogenesis through apoptosis-coupled phagocytosis. Cell Stem Cell 7:483-495. CrossRef Medline

Silva A, Pereira J, Oliveira CR, Relvas JB, Rego AC (2009) BDNF and extracellular matrix regulate differentiation of mice neurosphere-derived cells into a GABAergic neuronal phenotype. J Neurosci Res 87:1986-1996. CrossRef Medline

Sun L, Lee J, Fine HA (2004) Neuronally expressed stem cell factor induces neural stem cell migration to areas of brain injury. J Clin Invest 113:13641374. CrossRef Medline

Thiyagarajan M, Fernández JA, Lane SM, Griffin JH, Zlokovic BV (2008) Activated protein $\mathrm{C}$ promotes neovascularization and neurogenesis in postischemic brain via protease-activated receptor 1. J Neurosci 28 : 12788-12797. CrossRef Medline

Walker CT, Marky AH, Petraglia AL, Ali T, Chow N, Zlokovic BV (2010) Activated protein $\mathrm{C}$ analog with reduced anticoagulant activity improves functional recovery and reduces bleeding risk following controlled cortical impact. Brain Res 1347:125-131. CrossRef Medline

Wang L, Gang Zhang Z, Lan Zhang R, Chopp M (2005) Activation of the PI3-K/Akt pathway mediates cGMP enhanced-neurogenesis in the adult progenitor cells derived from the subventricular zone. J Cereb Blood Flow Metab 25:1150-1158. CrossRef Medline

Wang S, Chandler-Militello D, Lu G, Roy NS, Zielke A, Auvergne R, Stanwood N, Geschwind D, Coppola G, Nicolis SK, Sim FJ, Goldman SA (2010) Prospective identification, isolation, and profiling of a telomerase-expressing subpopulation of human neural stem cells, using sox2 enhancer-directed fluorescence-activated cell sorting. J Neurosci 30: 14635-14648. CrossRef Medline

Wang Y, Thiyagarajan M, Chow N, Singh I, Guo H, Davis TP, Zlokovic BV (2009) Differential neuroprotection and risk for bleeding from activated protein $\mathrm{C}$ with varying degrees of anticoagulant activity. Stroke 40:1864-1869. CrossRef Medline

Wang Y, Zhang Z, Chow N, Davis TP, Griffin JH, Chopp M, Zlokovic BV (2012) An activated protein $C$ analog with reduced anticoagulant activity extends the therapeutic window of tissue plasminogen activator for ischemic stroke in rodents. Stroke 43:2444-2449. CrossRef Medline

Williams PD, Zlokovic BV, Griffin JH, Pryor KE, Davis TP (2012) Preclinical safety and pharmacokinetic profile of 3K3A-APC, a novel, modified activated protein C for ischemic stroke. Curr Pharm Des 18:4215-4222. CrossRef Medline

Zhong Z, Ilieva H, Hallagan L, Bell R, Singh I, Paquette N, Thiyagarajan M, Deane R, Fernandez JA, Lane S, Zlokovic AB, Liu T, Griffin JH, Chow N, Castellino FJ, Stojanovic K, Cleveland DW, Zlokovic BV (2009) Activated protein $\mathrm{C}$ therapy slows ALS-like disease in mice by transcription- 
ally inhibiting SOD1 in motor neurons and microglia cells. J Clin Invest 119:3437-3449. CrossRef Medline

Zlokovic BV (2011) Neurovascular pathways to neurodegeneration in Alzheimer's disease and other disorders. Nat Rev Neurosci 12:723-738. CrossRef Medline
Zlokovic BV, Griffin JH (2011) Cytoprotective protein C pathways and implications for stroke and neurological disorders. Trends Neurosci 34: 198-209. CrossRef Medline 